\title{
A COMBINED STUDY OF FLOOD PROPAGATION MAPPING, USING SENTINEL-1 AND LANDSAT-8 DATA. A CASE STUDY FROM RIVER EVROS, GREECE
}

\author{
Kyriou A. ${ }^{1}$ and Nikolakopoulos K. ${ }^{1}$ \\ ${ }^{1}$ University of Patras, Department of Geology, 54124, Patra, Greece, knikolakop@ upatras.gr, \\ geo11060@upnet.gr
}

\begin{abstract}
Floods are suddenly and temporary natural disasters, which influence equally important the society and the natural environment, affecting areas that are not normally covered by water. In the context of flood mapping, different remote sensing techniques may contribute in a sufficient and effective way. This paper deals with mapping the spread of water bodies from natural levees of the river Evros and therefore the flood event on the surrounding areas of the river. In this work, radar data from Sentinel-1 mission as well as optical data from Landsat-8 were utilized. Specifically, Sentinel-1 data before flood events were treated with respectively during flood, yielding an image which reflects the propagation of the event. Moreover, Landsat-8 data were acquired with the aim of identifying and mapping of flooded areas, utilizing the Normalized Difference Water Index calculation. The results of the two methods were compared and flooded areas were evaluated.

Keywords: flood expansion, remote sensing, radar data, optical data, NDWI.
\end{abstract}

\section{Пєрí $\lambda \psi \eta$}

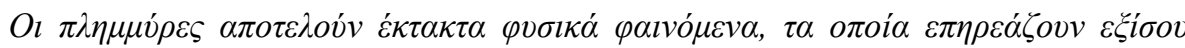

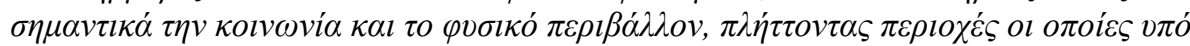

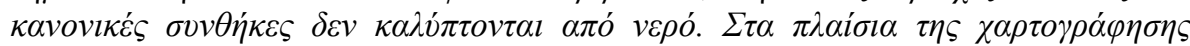

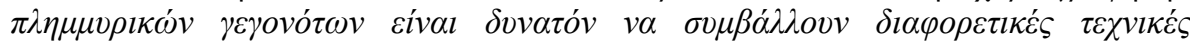

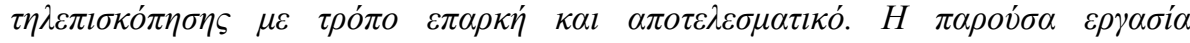

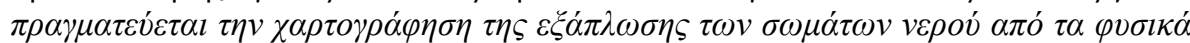

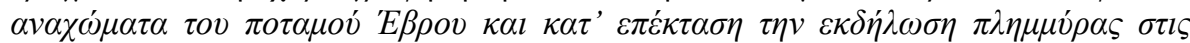

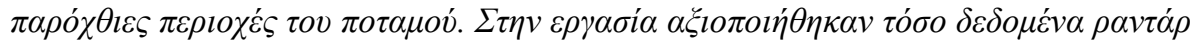

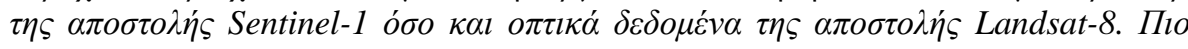

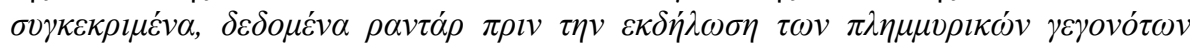

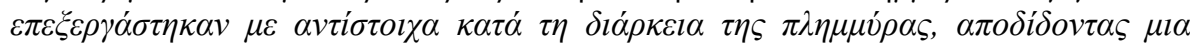

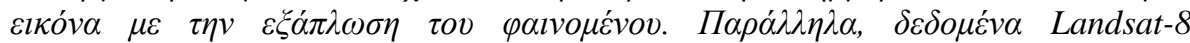

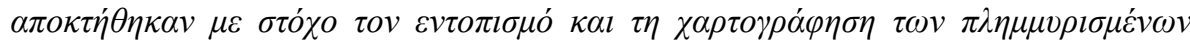

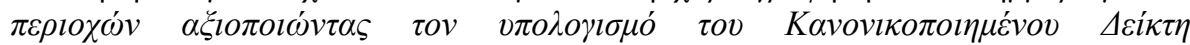

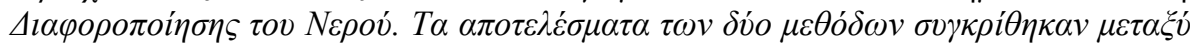

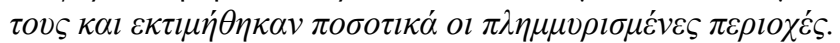

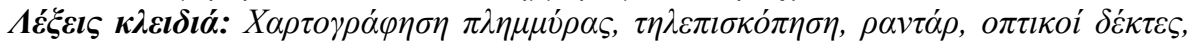
NDWI. 


\section{Introduction}

Floods are natural disasters and one of the most common hazards all over the world, erupting suddenly and affecting local communities. A flood covers by water land which is normally dry by overtopping the natural boundaries of the river due to increasing accumulation of rainwater or snow melt water that cannot handle by the capacity of the river channel. Due to the criticality of flood events, several studies have been front with the issue of flood propagation mapping and different techniques have been developed exploiting optical data as well as radar data. Regarding flood mapping utilizing optical data, the procedure is based on the calculation of Normalized Difference Water Index (NDWI). First approaches were associated the Normalized Difference Vegetation Index (NDVI) calculation with the NDWI estimation on farmland areas, in order to distinguish the dry parts and the saturated with water parts $(\mathrm{Gao}, 1996)$. In respective studies, the relevance of NDWI and NDVI indexes on mapping of flooded areas was examined, proving that the indexes extract satisfactory results, which are related to canal density (Sahu, 2014) and their exploiting could provide significant information about vegetation water content on agriculture (Jackson et al., 2004). A similar study focused on the correlation between NDWI and NDVI using Landsat-8 data and took into consideration different intensities of precipitation in each season of the year (Nascimento et al., 2015). In general, NDWI estimation could lead to different results depending on the different band combinations as well as different proportions of subpixel water/non-water components. In that context, data from Landsat ETM+, SPOT-5, ASTER, and MODIS were obtained with the aim of NDWI computation. The results were demonstrated that the use of green-SWIR band combination was efficient for NDWI calculation (Ji et al., 2009). A later approach was exploited the development of MIR band instead of a NIR band on NDWI estimation and the new index was known as Modified Normalized Difference Water Index (MNDWI). MNDWI gave the possibility of discrimination of water and non-water features, while it was more suitable in built-up land areas, since it can detract built up land noise (Xu, 2006). Additional, evaluation of NDWI using ALI, Thematic Mapper (TM), and Enhanced Thematic Mapper Plus (ETM+) data for land surface water mapping was applied in the Yangtze River Basin, China, investigating the higher mapping accuracies that run out of the green-SWIR band combination on the calculation ( $\mathrm{Li}$ et al., 2013). These results are in line with corresponding of a relative study, which proved that the specific Landsat- 8 bands provide better results on Xu's NDWI computation than McFeeter's NDWI (Du et al., 2014). Another new approach for surface water mapping was developed. The method was based on Principal Components of NDWI, using Landsat ETM+, TM and OLI data and the results were turned out the effectiveness of the technique (Rokni et al., 2014).

Concerning flood propagation mapping utilizing radar data several studies have been implemented, also. In one of the early attempts, ERS-1 satellite images were used in combination with digital elevation models and previous ancillary data, in order to map the flooded areas in Northern Italy. The satisfactory results were revealed the fitness and the rapidness of the method (Maggi et al., 1998). In later periods, new missions, like COSMO-Skymed provide data for real time creation of flood maps. A related study exhibited a detailed description of the methodology of the flood maps using COSMO-Skymed data and several case studies were referred, demonstrating the suitability of the approach for flood propagation mapping, but also noting some critical aspects (Pierdicca et al., 2012; Pulvirenti et al., 2009). In a respective study, an algorithm was created with the aim of discrimination of the flooded areas. The algorithm, working on $\mathrm{X}$ frequency band, distinguished the area in flooded and non flooded parts and it takes into consideration forest and agricultural flooded areas (Pulvirenti et al., 2011). Also, Radarsat data were utilized for flood mapping of forested wetlands of Roanoke river, North Carolina. The effectiveness of the data was confirmed with data of local wells, provided by U.S. Geological Survey (Townsend, 2001). In addition, COSMOSkymed data were combined with a hydrodynamic model with the view of the interpretation of the dynamics of a flood in January 2010 in Albania, revealing the agreement between the two approaches (Pulvirenti et al., 2014). Another procedure combined ALOS PALSAR images and GDEM ASTER for assessing potential flood hazards in Vietnam. On the advantages of the method 
belongs the effectiveness when hydrological and meteorological data as well as remote sensing images are inadequate (Huong et al., 2014). Surface water maps are possible to extract from an automatic processing algorithm, using ASAR and MODIS data and improving the final results with applying height above nearest drainage (HAND) index (Westerhoff et al, 2013) or otherwise using spaceborne radar data in combination with multialgorithms (Schumann et al., 2009). Furthermore, flood hazard management may be accomplished utilizing radar data in comparison with a simulation of a valid hydraulic flood model (Schumann et al., 2007).

This work combines optical and radar data for flood propagation mapping, utilizing radar data from Sentinel-1 and multispectral data from Landsat-8. Due to the fact that intense rainfalls during the wet season caused the eruption of flood events at the wider region of Evros, that area was defined as the study area. A similar approach of Evros flood events had been investigated though classification of flooded areas utilizing Landsat TM imagery (Ireland, 2015). The following paper is structured of four sections. Specifically, in the first part of the paper a few about Evros's study area and flood events are presenting. In the middle part flood mapping methodologies are going to be analyzed and flooded areas were estimated. Finally, results and conclusions are listed.

\section{Floods and Study area}

\subsection{Study Area}

Evros Prefecture is located in the north-eastern part of Greece and it represents a natural border of Greece with Bulgaria to the north and Turkey to the east (Figure 1). Evros river is the largest in the Balkans and the second larger in Europe, due to the facts the river offers its name to Evros Prefecture. In addition, it springs from Rila, Western Bulgaria and it flows southeast with a total length of about $530 \mathrm{~km}$. Concerning the Greek part of the river, the length of Evros is calculated about $206 \mathrm{~km}$ and the main tributaries are Tonzos (Tountzas), Ergina, Ardas and Erythropotamos. Evros empties into the northern Aegean Sea, in the so called Thracian Sea, developing a huge and labyrinthine delta at its estuary area. That delta is one of Europe's most important wetlands and it is under protection. Generally, Evros Prefecture is mainly lowland with a smooth relief. Specifically, only 424 sq. $\mathrm{km}$ of $4.242 \mathrm{sq} . \mathrm{km}$ of land area are mountainous, covering the western parth of the Prefecture, while the lowlands are $2.578 \mathrm{sq} \mathrm{km}$ and $1.240 \mathrm{sq}$. $\mathrm{km}$ are hilly, occupying the eastern part.

\subsection{Evros's Floods}

The climate of Evros is characterized as continental with harsh winters and hot summers. The annual temperature range higher than $20^{\circ} \mathrm{C}$ and in the cold season snow and frost are common for many days. Furthermore, due to an anticyclone system, continental polar or arctic masses moved and as a result, the winter temperatures are too low, contrary to the summer temperatures that reach to $40^{\circ}$ C. Rains tend to be distributed evenly though out the year but they don't disappear during the warm season and several times they are turned into thermal storms. The hydrological year of 2014-2015, three major flood events were struck Evros's region, during December, February and March (Table 1). The intense rains were caused an increase on the amount of water bodies, which are normally identified at Evros channel and as a result water overtopped the natural levees of the channel, so floods were erupted.

Table 1- Floods Events of 2014-2015, Related with Rainwater.

\begin{tabular}{|l|l|l|}
\hline \multicolumn{1}{|c|}{ A/A Flood events } & \multicolumn{1}{|c|}{ Date } & Average Monthly Precipitation \\
\hline 1 & $12 / 12 / 2014$ & $85.0 \mathrm{~mm}$ \\
\hline 2 & $22 / 02 / 2015$ & $56.5 \mathrm{~mm}$ \\
\hline 3 & $06 / 03 / 2015$ & $48.6 \mathrm{~mm}$ \\
\hline
\end{tabular}




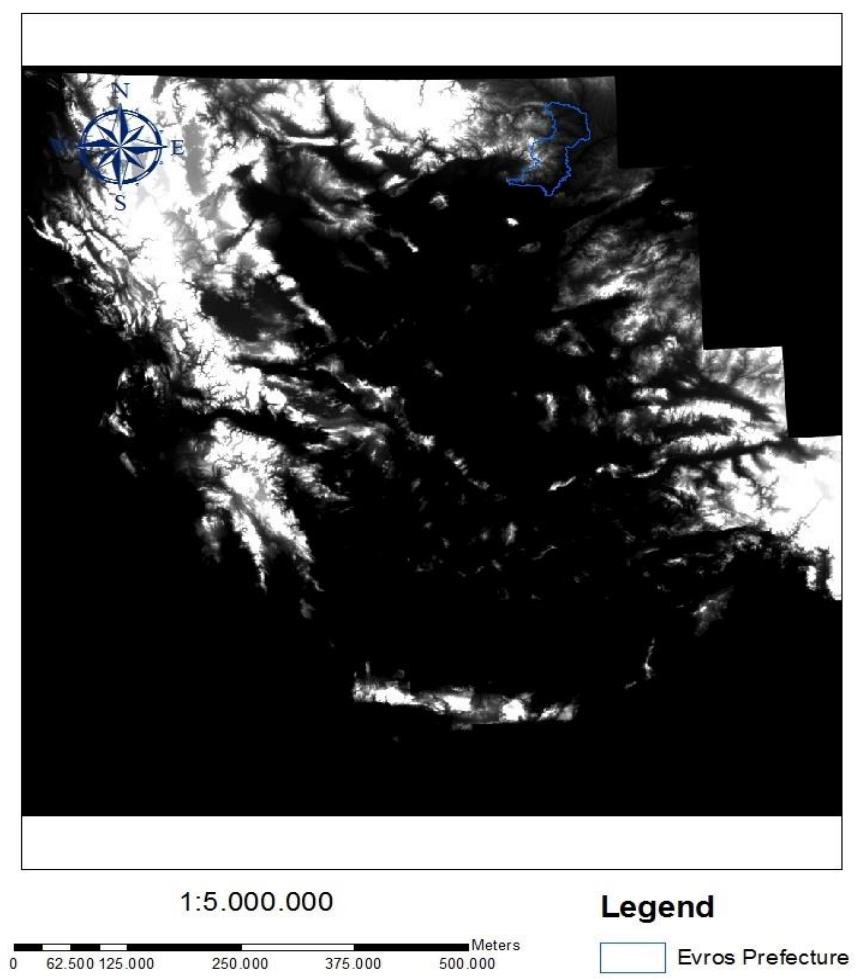

Figure 1 - Evros Prefecture.

\section{Flood Mapping Methodologies}

\subsection{Flood Mapping from Radar Data}

The capable of receiving data regardless weather conditions, is the main advantage of the radar sensors which makes the use of their data as satisfactory approach in flood mapping studies. In particular, the reflectance of radar's backscatter with the roughness water's surface constitutes the basic principle of flood propagation mapping. Water bodies create a smooth and homogeneous surface, which imprint with black or very dark colors in the radar image, while the surrounding dry land produces a stronger return, so the colors are brighter. Sentinel-1 mission provides timely data, therefore Sentinel-1 data were utilized for mapping Evros's floods (Table 2).

Table 2 - Sentinel-1 Data.

\begin{tabular}{|l|l|l|}
\hline \multicolumn{1}{|c|}{ Satellite } & \multicolumn{1}{c|}{ Mode } & \multicolumn{1}{c|}{ Date } \\
\hline Sentinel-1 & IW_SLC_1SDV & $25 / 10 / 2014$ \\
\hline Sentinel-1 & IW_SLC_1SDV & $12 / 12 / 2014$ \\
\hline Sentinel-1 & IW_SLC_1SDV & $17 / 01 / 2015$ \\
\hline Sentinel-1 & IW_SLC_1SDV & $22 / 02 / 2015$ \\
\hline Sentinel-1 & IW_SLC_1SDV & $06 / 03 / 2015$ \\
\hline
\end{tabular}

One of the major steps of the specific procedure is the distinction between the permanent water bodies and the flooded areas. On this, an image acquired during the flood event, called "crisis image" was compared with an another image obtained before the flood event, named "archive image". In 
case of Evros floods, five images were obtained, four of them during the wet period and one of them was acquired at the beginning of the hydrological year with the same sensor geometry. Flood propagation mapping process took place for each flood event in separate, following specific steps. Specifically, in an initial level of the procedure, Sentinel-1 data were submitted to Terrain Observation with Progressive Scans SAR (TOPSAR) technique in order to provide large swath widths by joining the bursts and improve radiometric performance by reducing the scalloping effect. Additional, the data were orthorectified utilizing a DEM and then a stacked image was created with the aim of comparison the images. Quantification of the magnitude of the flooding requires determining thresholds for categorization the area in flooded and non-flooded parts. That categorization arises from the definition of a logical math expression. The results of flood mapping for each flood event present in Figure 2, Figure 3, Figure 4 and Figure 5.

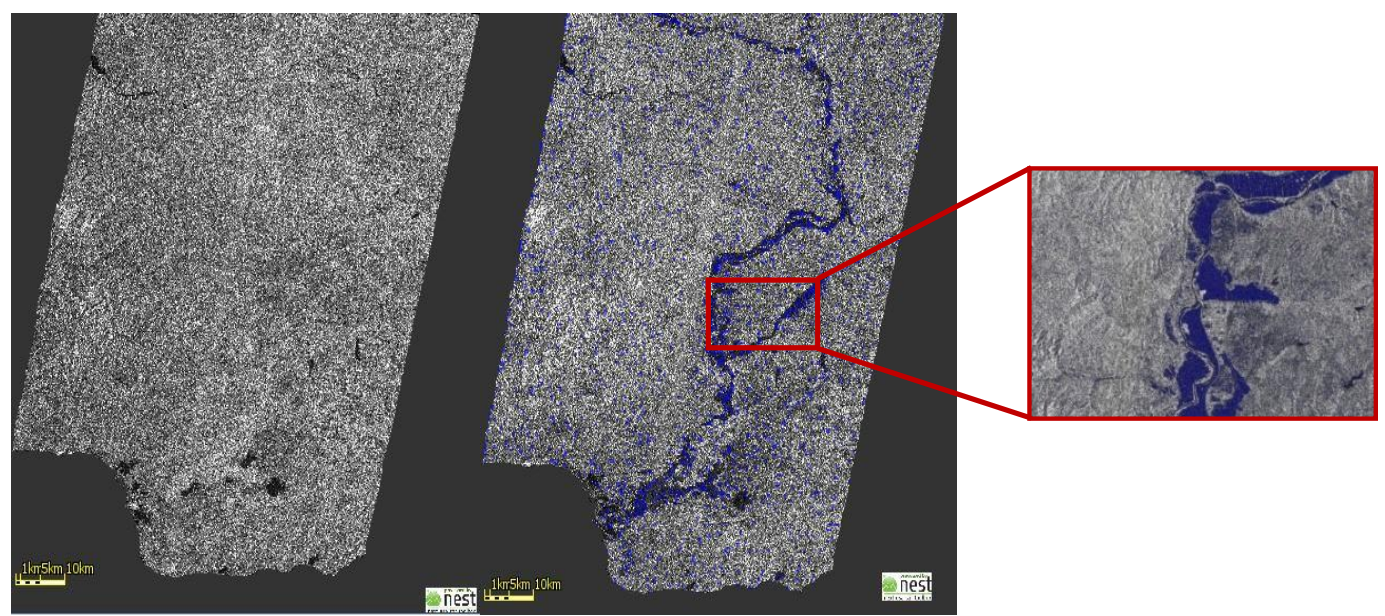

Figure 2 - Sentinel-1 data from Evros before the flood event in October of 2014 (left). Sentinel-1 data during December's flood and the final product of flood mapping (right).

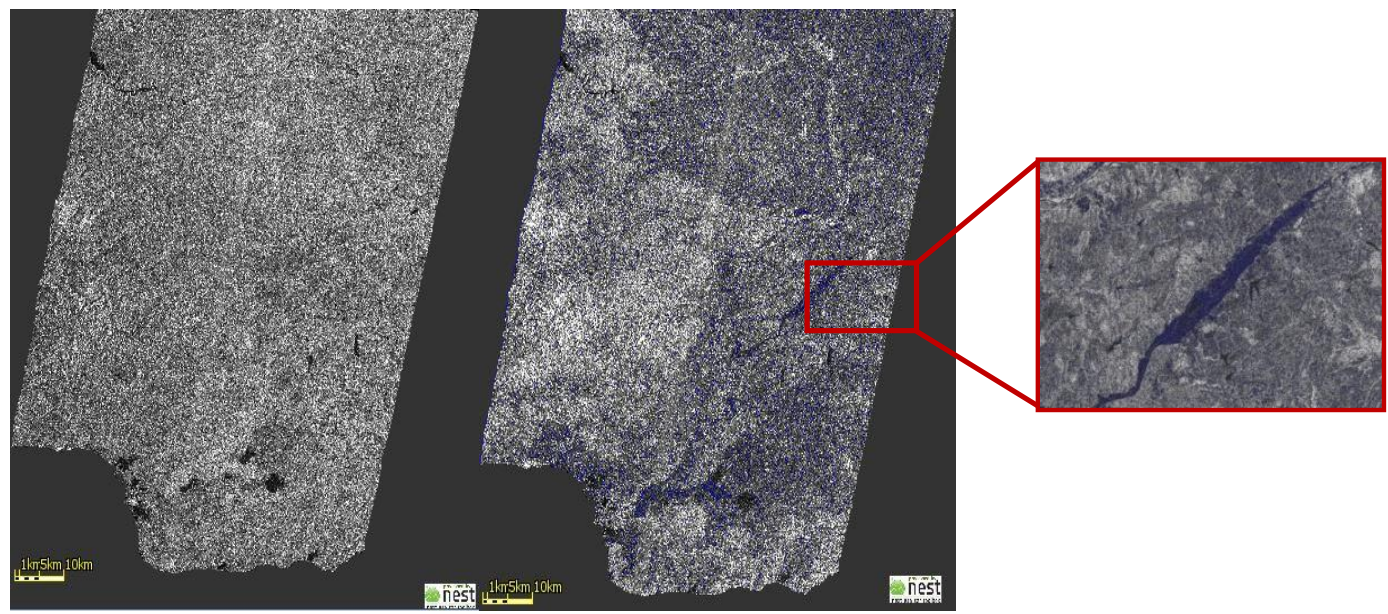

Figure 3 - Sentinel-1 data from Evros before the flood event in October of 2014 (left). Sentinel-1 data during January's flood and the final product of flood mapping (right). 


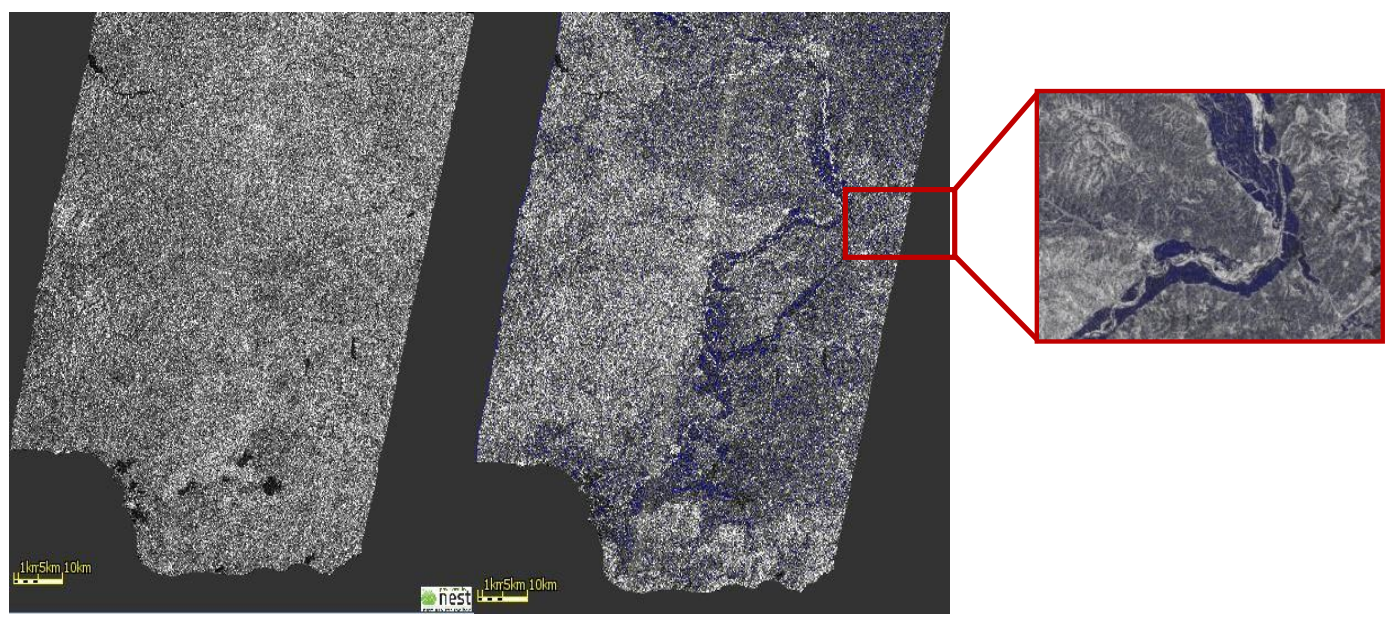

Figure 4 - Sentinel-1 data from Evros before the flood event in October of 2014 (left). Sentinel-1 data during February's flood and the final product of flood mapping (right).

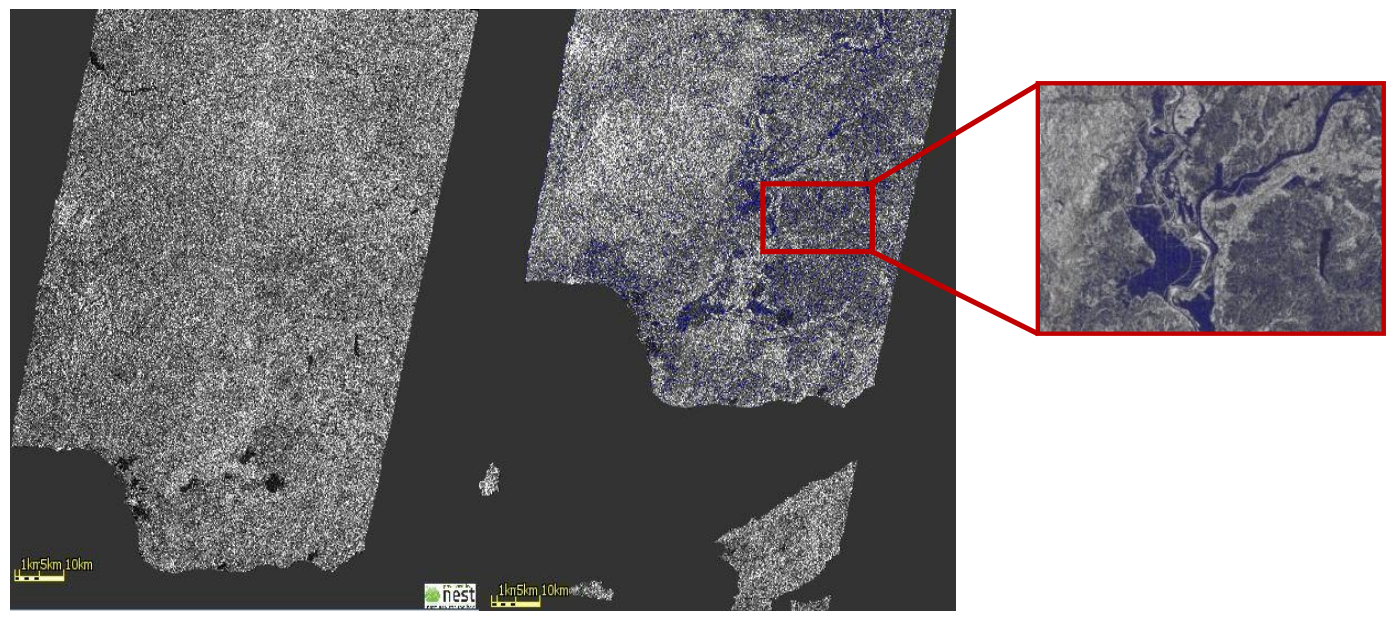

Figure 5 - Sentinel-1 data from Evros before the flood event in October of 2014 (left). Sentinel-1 data during March's flood and the final product of flood mapping (right).

\subsection{Flood Mapping from Optical Data}

On the other hand a different approach for flood propagation mapping recommends the use of optical data. Landsat-8 mission is equipped with a two sensor payload, the Operational Land Imager (OLI) and Thermal InfraRed Sensor (TIRS), which give the opportunity to gather nine spectral bands from the OLI, seven of them are multispectral, one Panchromatic band and a cirrus band. In addition the mission characterized of continued acquisition, availability, a spatial resolution of $30 \mathrm{~m}$ and a small revisiting period, that make Landsat- 8 data ideal for earth monitoring. In Evros case, four Landsat8 data, which are shown in Table 3, were obtained in order to implement a flood expansion research.

In order to detect and map flooded areas, using optical data, Normalized Difference Water Index (NDWI) was calculated. First steps of calculation require the conversion of digital numbers (DN) to radiance values through equation 1 . 
Equation 1 - Formula for conversion of digital numbers (DN) to radiance values

(Analysis of Landsat-8 OLI imagery for land surface water mapping, Du et al., 2014)

$L_{\lambda}=M_{L} \times Q c a l+A_{1}$

where $\mathrm{L}_{\lambda}$ is the top-of-atmosphere (TOA) spectral radiance, $\mathrm{M}_{\mathrm{L}}$ is band specific multiplicative rescaling factor from the metadata, $A_{1}$ is the band specific additive rescaling factor from the metadata. Then, aiming to remove cosine effect, compensate the exo-atmospheric solar irradiance and rectify variation in the earth-sun distance, TOA was evaluated by equation 2 .

\section{Equation 2 - Top-of-atmosphere evaluation}

(A comparison of land surface water mapping using the normalized difference water index from TM, ETM+ and ALI, Li et al., 2013)

$$
\rho_{\lambda}=\frac{\pi \times L_{\lambda} \times d^{2}}{E S U N_{\lambda} \times \cos \theta_{s}}
$$

where $\rho_{\lambda}$ is the TOA reflectance of wavelength $\lambda, \mathrm{d}$ is the earth-sun distance, ESUN $\mathrm{N}_{\lambda}$ is mean exoatmospheric solar irradiance, $\theta_{\mathrm{s}}$ is the solar zenith angle and $\mathrm{L}_{\lambda}$ is the spectral radiance at the sensor. Subsequently, two spectral water index methods were applied, NDWI and Modified NDWI (MNDWI). The NDWI is defined as it can be noted in equation 3.

\section{Equation 3 - Normalized Difference Water Index Calculation}

(A comparison of land surface water mapping using the normalized difference water index from TM, ETM+ and ALI, Li et al., 2013)

$$
N D W I=\frac{\rho_{\text {GREEN }}-\rho_{\text {NIR }}}{\rho_{\text {GREEN }}+\rho_{\text {NIR }}}
$$

where $\rho_{\text {Green }}$ and $\rho_{\text {NIR }}$ are the reflectance of the green and NIR bands and in case of Landsat- 8 this bands are band 3 and band 5 respectively. While MNDWI is defined as it can be noted equation 4 .

\section{Equation 4 - Modified Normalized Difference Water Index Calculation}

(A comparison of land surface water mapping using the normalized difference water index from TM, ETM+ and ALI, Li et al., 2013)

$$
M N D W I=\frac{\rho_{\text {GREEN }}-\rho_{\text {SWIR }}}{\rho_{\text {GREEN }}+\rho_{\text {SWIR }}}
$$

where $\rho_{\text {SWIR }}$ is the reflectance in the SWIR band and for Landsat- 8 the corresponding band is band 7.Aiming flood propagation mapping, NDWI models were created and they are presenting in figure 6, while MNDWI models were generated also and they are showing in figure 7 . The NDWI was calculated using green and NIR bands, specifically band 3 and band 5 of Landsat- 8 were utilized $\left(\mathrm{NDWI}_{\mathrm{T} 3,5}\right)$. The MNDWI was estimated using green and SWIR bands, namely band 3 and band 7 of Landsat-8 were exploited $\left(\mathrm{NDWI}_{\mathrm{T} 3,7}\right)$. As it seems, MNDWI produces better and clearer results than NDWI, because open water absorbs more intense MIR light than NIR light, as much as soil and vegetation reflect more MIR than NIR light.

In the context of a better visual flood expansion, a model that subtracts MNWDI images was used. From the MNDWI image of October 2014 the respective MNDWIs images of the wetland period were subtracted and the results are presented in figure 8 . As it seems, December flood was greater 
than November one, while April's flood was affected by snowmelt in Bulgaria and in the image was presented more intense. Additionally, flooded areas of each event were digitized.

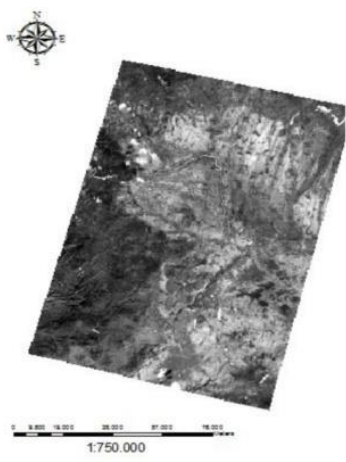

a.

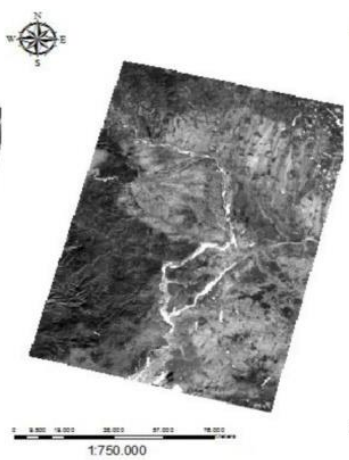

b.

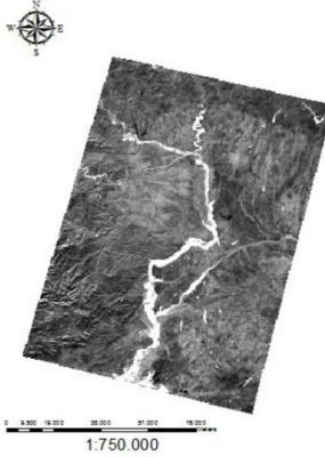

c.

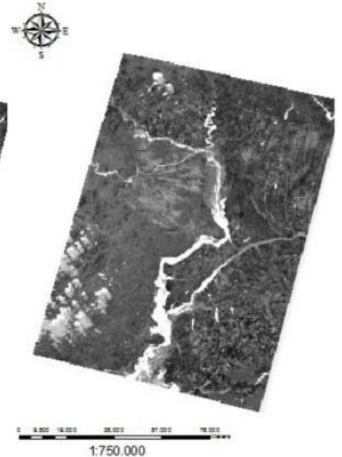

d.

Figure 6 - NDWI model of October (a), November (b), December (c) and April (d).

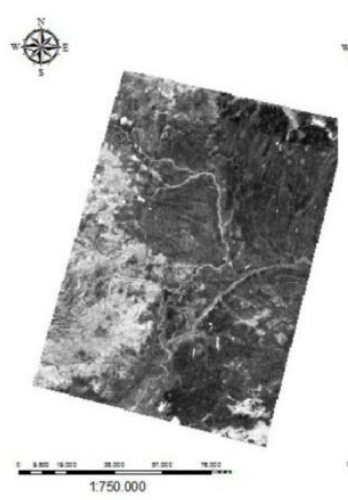

a.

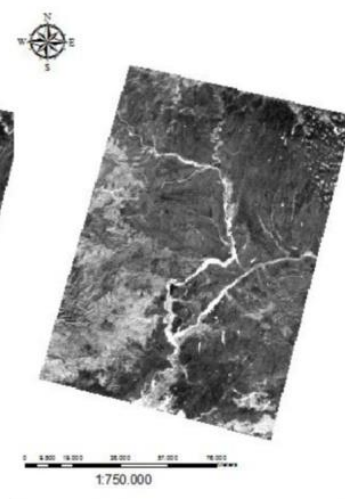

b.

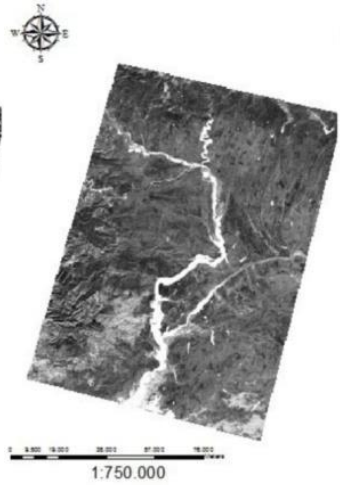

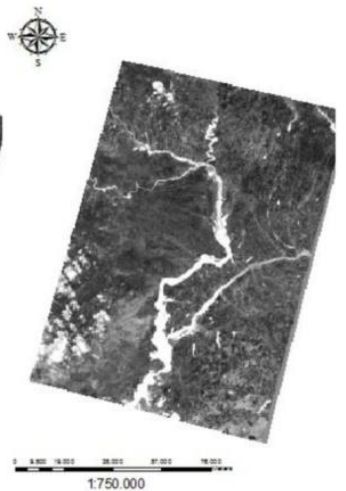

d.

Figure 7 - MNDWI model of October (a), November (b), December (c) and April (d).
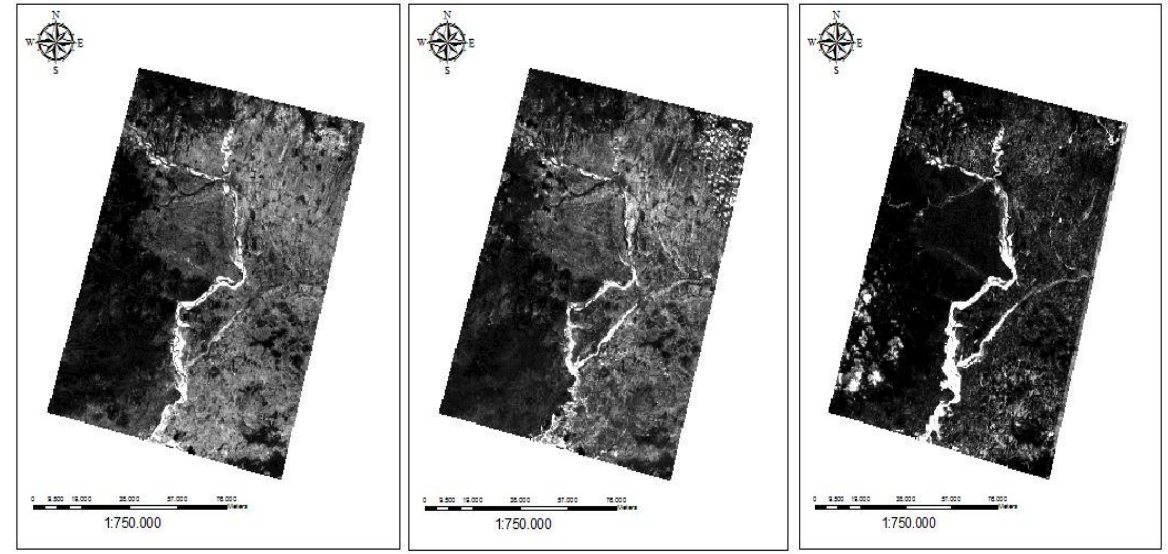

Figure 8 - Left: Difference of MNDWI(November 2014)- MNDWI(October 2014), Middle: Difference of MNDWI(December 2014)- MNDWI(October 2014), Right: Difference of MNDWI(April 2015)- MNDWI(October 2014). 
Table 3 - Landsat-8 Data.

\begin{tabular}{|l|l|l|l|l|l|}
\hline \multicolumn{1}{|c|}{ Satellite } & \multicolumn{1}{c|}{ Sensor } & \multicolumn{1}{c|}{ Date } & \multicolumn{1}{c|}{ Path } & \multicolumn{1}{c|}{ Row } & \multicolumn{1}{c|}{ Format } \\
\hline Landsat-8 & OLI TIRS & $19 / 10 / 2014$ & 182 & 31 & Geotiff \\
\hline Landsat-8 & OLI TIRS & $04 / 11 / 2014$ & 182 & 31 & Geotiff \\
\hline Landsat-8 & OLI TIRS & $22 / 12 / 2014$ & 182 & 31 & Geotiff \\
\hline Landsat-8 & OLI TIRS & $13 / 04 / 2015$ & 182 & 31 & Geotiff \\
\hline
\end{tabular}

\section{Flooded area estimation}

Finally, flooded areas of every method were computed and a few of the results are presented in table 4. It worth mentioning that calculated flooded areas of the radar data were similar to the respective areas of optical data during the same month. Due to the cloudiness in March, it was not possible acquiring optical data, so comparing comprises radar data from March and optical data from April. Results appeared close but it should not be forgotten that April's water bodies are expanded by snowmelt water in Bulgaria. Regarding differentiations in results, they could be arising of the different features or the remote sensing sensors (orbit, acquisition etc.) as much as differentiated processing.

Table 4 - Calculation of flooded areas.

\begin{tabular}{|l|l|}
\hline \multicolumn{1}{|c|}{ Data } & \multicolumn{1}{c|}{ Flooded area } \\
\hline Sentinel-1 (December 2014) & $990.793 \mathrm{~km}^{2}$ \\
\hline Landsat-8 (December 2014) & $821.970 \mathrm{~km}^{2}$ \\
\hline MNDWI difference of December-October & $889.505 \mathrm{~km}^{2}$ \\
\hline Sentinel-1 (March 2015) & $597.701 \mathrm{~km}^{2}$ \\
\hline Landsat-8 classification (April 2015) & $557.854 \mathrm{~km}^{2}$ \\
\hline Landsat-8 digitized (April 2015) & $538.329 \mathrm{~km}^{2}$ \\
\hline MNDWI difference of April-October & $330.851 \mathrm{~km}^{2}$ \\
\hline
\end{tabular}

\section{Results}

In conclusion, flood propagation mapping is possible to achieve so utilizing radar data, as much as multispectral data. Both methodologies provide satisfactorily results and could be applied in flood hazard management, as well as in emergency situations. Concerning radar flood mapping with Sentinel-1, the data were obtained independent of weather condition, so the user has the opportunity of timely data. However, flood mapping using radar data is based on researcher judgment since he sets the math expression that classify the area in flooded and non-flooded parts. On the other hand, Landsat- 8 multispectral data are affected from weather conditions may not be available due to the cloud cover of the study area. Nevertheless, flood mapping process using multispectral Landsat- 8 data, is more automated and is independent of researcher crisis, permitting a wide range of comparison. Furthermore Landsat- 8 data were more operational and handy than Sentinel-1 data. Also, it was noted that MNDWI provided better results on flood mapping process, since the flooded areas were revealed more clearly. Finally, the estimated flooded areas of the two techniques seemed to agree with minor variations arising primarily from the characteristics of each mission.

\section{References}

Du, Z., Li, W., Zhou, D., Tian, L. and Ling, F., 2014. Analysis of Landsat-8 OLI imagery for land surface water mapping, Remote Sensing Letters, 5(7), 37-41. 
Gao, B.C., 1996. NDWI - A normalized difference water index for remote sensing of vegetation liquid water from space, Remote Sensing of Environment, 58, 257-266.

Huong, D. and Ryota, N., 2014, Potential flood hazard assessment by integration of ALOS PALSAR and ASTER GDEM: a case study for the Hoa Chau commune, Hoa Vang district, in central Vietnam, Journal of Applied Remote Sensing, 8, 083626-1 - 083626-12.

Ireland, G., Volpi, M. and Petropoulos, G., 2015.Examining the Capability of Supervised Machine Learning Classifiers in Extracting Flooded Areas from Landsat TM Imagery: A Case Study from a Mediterranean Flood, Remote Sensing, 7, 3372-3399.

Jackson, T.J., Chen, D., Cosh, M., Li, F., Anderson, M., Walthall, C., Doriaswamy, P. and Hunt, E.R.,2004. Vegetation water content mapping using Landsat data derived normalized difference water index for corn and soybeans, Remote Sensing of Environment, 92, 475-482.

Ji, L., Zhang, L. and Wylie, B., 2009. Analysis of Dynamic Thresholds for the Normalized Difference Water Index, Photogrammetric Engineering \& Remote Sensing, 75(11), 13071317.

Li, W., Du, Z., Ling, F., Zhou, D., Wang, H., Gui, Y., Sun, B. and Zhang, X., 2013. A comparison of land surface water mapping using the normalized difference water index from TM, ETM+ and ALI, Remote Sensing, 5, 5530-5549.

Maggi, M., Brivio, P., Colombo, R. and Tomasoni, R., 1998, Flooded areas estimation using radar images and digital elevation model, Proceedings of the EUROPTO Conference on Remote Sensing for Geology, Land Management, and Cultural Heritage Ill, Barcelona, Spain September 1998, SPIE, 3496, 46-53.

Nascimento, B., Schiavo, D.V., Ruza, M.S., Maria, Â., Hentz, K., Schikowski, A.B. and Dalla, A.P., 2015. Pluviometric Influence in the Indexes of NDVI and NDWI Vegetation for the Municipality of Guarapuava-PR, South Region of Brazil, Australian Journal of Basic and Applied Sciences, 9, 358-363.

Pierdicca, N., Chinib, M., Pulvirentia, L., Marzanoa, F. and Moria, S., 2012, Proceedings of SAR Image Analysis, Modeling and Techniques XII, SPIE, 8536, 85360W1- 85360W11.

Pulvirenti, L., Pierdicca, N., Chini, M. and Guerriero, L., 2011. An algorithm for operational flood mapping from Synthetic Aperture Radar (SAR) data using fuzzy logic, Natural Hazards and Earth System Sciences, 11, 529-540.

Pulvirenti, L., Pierdicca, N., Chinib, M. and Guerriero L., 2014, Combined use of COSMO-SkyMed derived products and hydrodynamic models to produce physically-based maps of flood extent, Proceedings of SAR Image Analysis, Modeling and Techniques XII, SPIE, 924, 92431C1- 92431C10.

Rokni, K., Ahmad, A., Selamat, A. and Hazini, S., 2014. Water feature extraction and change detection using multitemporal landsat imagery, Remote Sensing, 6, 4173-4189.

Sahu, A., 2014. Identification and mapping of the water-logged areas in Purba Medinipur part of Keleghai river basin, India: RS and GIS methods, International Journal of Advance Geoscience, 2(2), 59-65.

Schumann, G., Di Baldassarre, G. and Bates, P.D., 2009. The Utility of Spaceborne Radar to Render Flood Inundation Maps Based on Multialgorithm Ensembles, Geoscience and Remote Sensing, 47(8), 2801-2807.

Schumann, G., Hostache, R., Puech, C., Hoffmann, L., Matgen, P., Pappenberger, F. and Pfister, L., 2007. High-Resolution 3-D Flood Information from Radar Imagery for Flood Hazard Management, Geoscience and Remote Sensing, 45(6), 1715-1725.

Townsend, P.A., 2001. Mapping seasonal flooding in forested wetlands using multi-temporal Radarsat SAR, Photogrammetric Engineering \& Remote Sensing, 67, 857-864.

Westerhoff, R.S., Kleuskens, M.P.H., Winsemius, H.C., Huizinga, H.J., Brakenridge, G.R. and Bishop, C., 2013. Automated global water mapping based on wide-swath orbital syntheticaperture radar, Hydrology and Earth System Sciences, 17, 651-663.

$\mathrm{Xu}, \mathrm{H}$., 2006. Modification of normalised difference water index (NDWI) to enhance open water features in remotely sensed imagery, International Journal of Remote Sensing, 27, 30253033. 